\title{
Effects of Corporate Culture on Organization Performance
}

\author{
Joy Wangui Karanja \\ Jomo Kenyatta University of Agriculture and Technology (JKUAT)-Kenya
}

\begin{abstract}
This paper focuses on the definition of organizational/corporate culture and sheds the light on the important studies on the topic. Various definitions of corporate culture as discussed by various authors have been analyzed. The different types of cultures and what researchers have found out about their effects on organization performance has been reviewed in this paper.

A number of studies that linked the relationship between organizational culture and the organizational performance have been discussed. The researcher realized that as cited by Jennifer et al., (2011) the relationship between culture and organizational performance is still not well understood by many researchers. They bring out the criticism of strong and weak cultures citing that what matters is not the strength or weakness of a culture but how forcefully the norms are held by organizational members (its intensity), and how widely members agree about the norms within the organization (consensus) (O'Reilly, 1989; Jackson, 1960).

The researcher agrees with this finding as supported by Sørensen (2002) who theorized that an organization cultures lead to consistency in performance by increasing employee consensus and willingness to endorse organizational goals, reducing uncertainty through goal clarity, and increasing motivation. Although Wilderom and Berg (1998) argued that instead of striving for strong culture, researchers should attempt to reduce the gap between employees' preferred organizational culture practices and their perception of the organizational practices. This prompts a further study to explore the reasoning by Wilderom and Berg.

Key words: Corporate culture, Organization performance, Strong culture and organizational culture \& performance.
\end{abstract}

\section{Definition of culture}

\section{Background}

Fiol, (1991), O'Reilly \& Chatman, (1996) defines culture as a pattern of shared assumptions, beliefs, and expectations that guide members' interpretations and actions by defining appropriate behavior within an organization. A key unifying element of this definition is the shared nature of culture (e.g., Quinn, \& Rohrbaugh, 1983; Ravasi \& Schultz, 2006). According to the Webster's dictionary, culture is the ideas, customs, skills, arts, etc. of a given people in a given period. Astute managers have realized that any organization also has its own corporate culture.

\section{Definition of corporate culture}

Researchers have had differences about the explicitness of organizational culture, with some viewing culture as mostly tacit and implicit (e.g., Schein, 1985) and others focusing on its observable behavioral manifestations for example (Chatman, 1991; Carroll \& Harrison, 1998). Daulatram B. Lund, (2003) summarizes corporate culture as "the pattern of shared values and beliefs that help individuals understand organizational functioning and thus provide them with norms for behavior in the organization" (Deshpande and Webster, 19899, P. 4)

\section{Definition of Organizational Performance}

Barney, (1997) states that researchers among themselves have different opinions of performance. Performance, in fact, continues to be a contentious issue among organizational researchers. For example, according to Javier (2002), performance is equivalent to the famous 3Es (economy, efficiency, and effectiveness) of a certain program or activity. However, according to Daft (2000), organizational performance is the organization's ability to attain its goals by using resources in an efficient and effective manner. Quite similar to Daft (2000), Richardo (2001) defined organizational performance as the ability of the organization to achieve its goals and objectives.

According to Hansen and Wernerfelt (1989) in the business policy literature, there were two major streams of research on the determinants of organizational performance. One was based on economic tradition, emphasizing the importance of external market factors in determining organizational performance as explained in the Cameron and Freeman (1991) typology of cultures model. The other line of research was built on the behavioral and sociological paradigm and saw organizational factors and their 'fit' with the environment as the major determinant of success. 
Another study by Chien (2004) found that there were five major factors determining organizational performance, namely: Leadership styles and environment, Organizational culture, Job design, Model of motivation, and Human resource policies.

\section{Purpose Of The Paper}

The purpose of this paper is to highlight and analyze the different organization culture and their influence on organizational performance with a specific focus to reduce the gap between employees' preferred organizational culture practices and their perception of the organizational practices. Different views on how culture influences performance has been analyzed as well as relationship between culture and performance. Information gathered and the recommendations thereof will help to identify the optimal strategic approach in identifying the right culture to improve and sustain desirable performance. It will further, highlight some criticism on the effect of culture to organizational performance giving a flip side to prompt critical analysis in to the best approach to define the efficiency of an ideal culture that sustains the desired organizational performance.

\section{Different types of culture}

Jennifer, et al., (2011) focuses on cultural norms, which according to O'Reilly \& Chatman, (1996) are shared expectations about appropriate behaviors that emerge from an organization's values. Norms are socially created standards that help group members interpret and evaluate various events and actions. She continues to expound that cultural norms typically form around behaviors that are significant to a group such as how to interact with one another and prioritize objectives (e.g., Bettenhausen \& Murninghan, 1991). Cultural norms help people solicit and attend to the information and behaviors that are likely to be valued or useful within the organizational context (e.g., Ashford \& Northcraft, 1992).

Daulatram (2003) focuses on types of cultures characterized by a particular set of shared beliefs, style of leadership, set of shared values that act as a bond or glue for members and strategic emphases in pursuit of effectiveness. Cameron and Freeman (1991) identified a useful framework of organizational culture types by integrating the works of several researchers (Campbell, 1977; Jung, 1923; Mason and Mitroff, 1973; Mitroff and Kilmann, 1975; Quinn, 1988; Quinn and McGrath, 1985; Quinn and Rohrbaugh, 1983; Smircich, 1983; Wilkins and Ouchi, 1983 among others).

The framework is presented below which is based on four sets of attributes as outlined by Daulatram B. Lund (2003) in his journal "Organizational culture and Job satisfaction"

The dominant characteristics or values, the dominant style of leadership, the bases for bonding or coupling and the strategic emphasis present in the organization.

Fig. 1.

\section{ORGANIC PROCESSES (flexibility, spontaneity)}

Type: Clan

DOMINAT ATTRIBUTES:

Cohesiveness, participation, teamwork, sense of family

LEADER STYLE: Mentor, facilitator, parent-figure

BONDING: Loyalty, tradition, interpersonal cohesion

STRATEGIC EMPHASES: Toward developing human resources, commitment, morale

\section{INTERNAL MAINTENANCE} (smoothing activities, integration)

Type: Hierarchy
Type: Adhocracy

DOMINANT ATTRIBUTES: Entrepreneurship, creativity, adoptability

LEADERSHIP STYLE: Entrepreneur, innovator, risk taker

BONDING: Entrepreneurship, flexibility, risk

STRATEGIC EMPHASES: Towards innovation, growth, new resources

\author{
ETERNAL POSITIONING \\ (competition, differentiation)
}

Type: Market 
DOMINAT ATTRIBUTES:

Order, rules and regulations, uniformity

LEADER STYLE: Coordinator, administrator

BONDING: Rules, policies and procedures
DOMINAT ATTRIBUTES:

Competitiveness, goal achievement

LEADER STYLE: Decisive, achievement - orientated

BONDING: Goal orientation, production, competition

STRATEGIC EMPHASES: Toward competitive advantage and market superiority
STRATEGIC EMPHASES: Towards stability, predictability, smooth operations

\section{MECHANISTIC PROCESSES (control, order, stability)}

\section{Source: Adapted from Cameron and Freeman (1991)}

While validating the usefulness of the above typology of cultures, Desphande et al. (1993) emphasize that these culture types are modal or dominant ones rather than mutually exclusive ones. Most firms can and do have elements of several types of cultures. Therefore it follows that identifying a typology of cultures also makes it possible to determine if organizations are dominated by one type or have attributes of several types and this has a relationship with their performance.

Cameron and Quinn state that the significance of these clusters of organizational effectiveness criteria is that they "represent what people value about an organization's performance. They define what is seen as good right and appropriate and they define the core values on which judgments about organizations are made" (2006, p. 31).

Additionally, these quadrants represent opposite or competing values or assumptions. As you move, from left to right along the "Focus" (People - Organization) continuum or axis of the chart the emphasis shifts from an internal focus within the organization to that of an external focus outside the organization. As you move from the bottom of the chart along the "Structure" (Flexibility - Control) continuum or axis the emphasis shifts from control and stability within the organization and the environment to that of flexibility and discretion within the organization and the environment. The diagonal dimensions also produce conflicting or competing values. For example, the values in the upper right quadrant emphasize an external focus concerned with flexibility and growth, while the values in the lower left quadrant accentuate an internal focus with control and stability (Quinn and Rohrbaugh, 1983).

\section{Relationship Between Corporate Culture And Organizational Performance}

Denison and Mishra (1995) studied five firms and linked organizational culture attributes such as adaptability to growth and profitability, and both Kotter and Heskett (1992) and Gordon and DiTomaso (1992) found that firms emphasizing adaptability and change in their cultures were more likely to perform well over time, though the specific reasons for this relationship are unclear. But other research found inconclusive relationships between organizational culture and performance (e.g., Cameron \& Freeman, 1991; Wilderom, Lunk, \& Maslowski, 2000). But some researchers (e.g. Stewart 2007) mentioned that profitability being the organizational goal the best places to start improvements is with an examination of the organization's work culture. He states that the strongest component of the work culture is the beliefs and attitudes of the employees. It is the people who make up the culture, he stated.

"If these cultural norms contain beliefs such as, "Around here, nobody dares make waves" or, "Do just enough to get by and people will leave you alone," the organization's performance will reflect those beliefs. Moreover, if the cultural belief system contains positive approaches, such as, "Winners are rewarded here" or, "People really care if you do a good job," that also will be reflected in the organization's performance"

Stewart (2007) also stated that an organization's cultural norms strongly affect all who are involved in the organization. Those norms are almost invisible, but if we would like to improve performance and profitability, norms are one of the first places to look. Successful manager cannot leave the development of a high-performance work culture to chance if the business is not to risk its very future.

However, most important yet least understood question still remains; how organizational culture relates to organizational performance. Researchers initially favored a direct positive relationship, speculating that certain types of cultures led to better financial performance (e.g., Barney, 1986). The logic was that the clarity derived from salient shared norms that are strongly enforced among members would promote greater strategic alignment and goal attainment in strong-culture firms (e.g., Tushman \& O’Reilly, 2002). 
Although many studies have found that different companies in different countries tend to emphasize on different objectives, financial profitability and growth are the most common measures of organizational performance. Besides competition, both innovations and a cohesive culture determine the appropriateness of a firm's activities that can contribute to its performance. Organizational culture is not just an important factor of an organization; it is the central driver of superior business performance. In their article entitled "A Strong Market Culture Drives Organizational Performance and Success", Gallagher and Brown (2007) stated that a company's culture influences everything such a company does. It is the core of what the company is really like, how it operates, what it focuses on, and how it treats customers, employees, and shareholders. They also stated that between 1990 and 2007, more than 60 research studies covering 7,619 companies and small business units in 26 countries have found that market culture and business performance are strongly related. Thus confirming the relationship between corporate culture and organization performance. It also confirms that organizational culture must be adoptable to external environment for sustained competitive advantage as demonstrated by adhocracy and market cultures.

\section{Empirical Investigations Of Culture-Performance Relationships}

Critique against promises of using culture as a means for corporate goals have been raised. Much interest has nevertheless been given to effects on performance of the 'right' or strong enough corporate culture. There is a lot of writing and talk about this but also a few systematic empirical studies.

\section{Strong Culture}

According to Denison, (1984) argues that a strong-culture is attributed by the commitment of an organization's employees and managers to the same set of values, beliefs and norms will have positive results that the 'strength' of 'corporate culture' is directly correlated with the level of profits in a company. Researchers adopting this hypothesis tend to place new kinds of human relations (involving employees in decision-making, allowing them some discretion, developing holistic relations, etc.) at the core of organizational culture (e.g. Peters and Waterman, 1982; Ouchi, 1981). It is frequently argued that a distinct organizational culture contributes to performance through facilitating goal alignment - a common culture makes it easier to agree upon goals as well as appropriate means for attaining them. There are also positive effects on motivation a shared culture encourages people to identify with the organization and feel belongingness and responsibility for it (Brown, 1995).

However, some researchers such as Wilderom and Berg (1998) argued that instead of striving for strong culture, researchers should attempt to reduce the gap between employees' preferred organizational culture practices and their perception of the organizational practices.

Another idea draws upon contingency thinking to suggest that under certain conditions a particular type of culture is appropriate, even necessary, and contributes to efficiency. Wilkins and Ouchi (1983), for example, consider culture an important regulatory mechanism in organizational settings too complex and ambiguous to be controlled by traditional means (bureaucracy and the market) as outlined in the Cameron and Freeman (1991) topology of cultures model in fig 1 above. In corporate situations where these means of regulation function well, corporate control as a distinct form is less significant.

In their research paper "Organizational Culture and Performance in High-Technology Firms: The Effects of Culture Content and Strength" Jennifer et al., (2011) offers evidence that a strong culture is not necessarily a disadvantage in turbulent environments. Instead, whether culture strength is an advantage or disadvantage depends on both the content and strength of the culture. Firms with higher levels of consensus across many norms, as well as an intensive emphasis on adaptability which may promote conformity without the inertial effects of uniformity, performed better financially over a volatile three-year period.

\section{Weak Culture}

According to Rana A. et al., (2012) a weak culture of organization could be one that is loosely knit. Some time it may push individual thought, contributions and in a company that needs to grow through innovation, it could be a valuable asset, some time not. According to Deal and Kenndy (1982), a weak culture of organization could be one that is loosely joined-rules are imposed strictly on the employees that may create diversity between the person's personal objectives and organizational goals.

Both views fail to recognize that culture as a construct encompasses three dimensions: the content of norms (e.g., teamwork, integrity), how forcefully they are held by organizational members (its intensity), and how widely members agree about the norms within the organization (consensus).

We hypothesize that strong cultures will boost performance in dynamic environments if a norm of adaptability is intensely held and cultural norms are widely shared among members. 
However, (Jennifer, David, Charles and Bernadette 2011) has challenged this perspective citing that there is blurred a critical distinction between a culture's strength and its content. Further, researchers have often failed to recognize two distinct aspects of culture strength: the degree to which members agree about cultural norms (consensus) and the force (intensity) with which certain norms are held (O'Reilly, 1989; Jackson, 1966). They offer a suggestion that the contradictions in prior research can be resolved by recognizing that, even in dynamic environments, organizations that have intensity around a certain kind of cultural-norm - one that promotes nonuniform behaviors and adaptability in particular - and which are characterized by higher consensus among members about cultural norms, may perform better than those characterized either by lower consensus, lower intensity, or both. They provide a way to separate the measurement of culture content from culture strength.

The impact of strong versus weak situations on behavior have been observed by psychologists (e.g., Fleeson, 2007; Mischel, 1977) and they developed criteria for assessing a situation's strength. A situation is considered strong when it induces conformity; that is, it "...leads all persons to construe the particular events the same way" (Mischel, 1973: 276). Conversely, weak situations are ambiguous; they are neither collectively encoded nor do they generate or reward similar expectations or behavior. Many have argued that strong situations need also to be distinctive and identifiable so that people can reliably predict cause-effect relationships (e.g., Kelley, 1967; Meyer et al., 2010), but (Jeniffer et al. 2011) suggest that this confuses a situation's content with its strength. This is because content is more identifiable for some norms, but a norm's strength - represented partly by the extent to which people agree about its relative importance - is independent of its substance.

\section{Adaptive Cultures}

According to Daulatram B. Lund (2003) "Adaptive cultures" are the key to good performance, i.e. cultures that are able to respond to changes in the environment. Such cultures are characterized by people willing to take risk, trust each other, are proactive, work together to identify problems and opportunities, etc. It may be tempting to say that 'adaptive cultures' are self-evidently superior. There easily enters an element of tautology here: 'adaptive' implying successful adaption and this is per definition good for business. But as Brown (1995) remarks, there are organizations that are relatively stable and fit with a relatively stable environment, and risk-taking and innovation are not necessarily successful. Too much change can lead to instability, low cost-efficiency, risky projects and a loss of sense of direction.

(Brown, 1995; Calori and Sarnin, 1991; Siehl and Martin, 1990) cited that it is very difficult to investigate and test these diverse ideas on empirical studies on the culture-performance link. They found out that the idea of a corporate culture concept cannot be linked simply and tightly to corporate results. But according to Gallagher and Brown (2007) a company's culture influences everything a company does.

\section{Criticism On Effect Of Culture On Organization Performance}

Researchers initially favored a direct positive relationship, speculating that certain types of cultures led to better financial performance (e.g., Barney, 1986). The logic was that the clarity derived from salient shared norms that are strongly enforced among members would promote greater strategic alignment and goal attainment in strong-culture firms (e.g., Tushman \& O'Reilly, 2002).

Many have concluded that the link between organizational culture and firm performance lacks consistent and compelling support (e.g., Detert, Schroeder, \& Mauriel, 2000; Hartnell, Ou, \& Kinicki, 2011). In an effort to resolve these inconsistencies, some researchers have suggested that the relationship between culture and organizational performance is contingent on environmental conditions. One argument is that strong-culture firms may gain advantages in stable environments but, because of the corresponding social control that promotes conformity among members, they may perform worse or less reliably in dynamic environments and during periods of change (Sørensen, 2002; Van den Steen, 2005). Since many organizations operate in dynamic environments, this view suggests that strong cultures may reduce a firm's performance.

\section{Effect Of Organizational Culture On Corporate Performance}

The literature on organizational culture is rich and diverse. Much of its richness is founded on the claim that culture is linked to organizational performance. Even though there are some theorists that questioned the culture-performance link, sufficient evidence exists to suggest that organizational culture is associated with organizational performance. (Ogbonna and Harris, 2000)

One of the earliest quantitative studies on the culture-performance link was conducted by Denison (1984) who used data from 34 American firms over a five year period. The author examined characteristics of organizational culture in these firms and tracked their performance over time. To measure performance the author used data on returns on investment and sales. For organizational performance responses on a one time survey regarding the perceptions of work organization and participation in decision making were gathered. Although, the author found that organizational culture is correlated with financial performance, some of his 
measurement indicators differ in the strength of the relationship between culture and performance. Decision making and work design were associated with long term financial performance while supervisory leadership was associated with short term financial performance. Even though it has encouraging results, this study is not without limitations. The most important criticisms refer to the use of

employee perceptions which suggest that the study had obtained a measure of organizational climate rather than a measure of organizational culture (Lim, 1995).

Rousseau (1990) tried in his study to overcome some of the limitations in measuring organizational culture. He gathered data from 32 voluntary service organizations using as a performance measure the amount of money raised from a recently completed found-raising campaign and the Organizational Culture Inventory promoted by Cooke and Lafferty (1983) to measure organizational culture. The results of this study showed no significant positive correlations between performance and culture.

One of the most extensive studies on the culture-performance link was conducted by Kotter and Heskett (1992). They used data gathered from 207 firms over a five year period. In this study they used various measures of culture and long term economic performance data. Their initial objective was to examine the relationship between strong cultures and long term performance. Even though they found only a minor correlation between strong culture and long term performance, subsequent investigations showed that firms with cultures suited to their market environment have better performance than those that are less fitted to their environment.

Marcoulides and Heck (1993) analyzed the relationship between organizational culture and performance using data collected from 26 organizations. The authors proposed a model in which organizational culture was measured using several latent variables (organizational structure, organizational values, task organization, climate, and individual values and beliefs) and organizational performance was measured using capital, market and financial indicators. The results of this study showed that all of the latent variables used to measure organizational culture had some effect on performance with workers attitudes and task organization activities being the most significant variables.

Ogbonna and Harris (2000) analyzed the relationship between organizational culture and performance by including the leadership style as a third variable in the model. To measure performance they used variables such as: customer satisfaction, sales growth, market share, competitive advantage and sales volume. For organizational culture they used measures such as: competitive culture, innovative culture, bureaucratic culture and community culture. The results showed that all four measures of organizational culture were associated in some way with corporate performance. More specifically, innovative and competitive cultures had a direct effect on performance and accounted for approximately 25 percent of the variance in organizational performance. Both Adhocracy and Market cultures (competitive and innovative characteristics) were externally oriented in line with the assumption that organizational culture must be adaptable to external environment for a sustained competitive advantage. The Hierarchy and Clan cultures (bureaucratic and community characteristics), which were internally oriented, were not directly related to performance.

This study was extended in 2002 when the authors analyzed the link between market orientation, organizational culture, strategic human resource management and organizational performance. The authors used the same measures as in the previous study for organizational culture and performance. As in the previous study, Adhocracy and Market cultures were found to have a significant effect on performance while Clan and Hierarchy cultures were not related to performance.

\section{Conclusion}

Organizational culture is not just an important factor of an organization; it is the central driver of superior business performance. It is the core of what the company is really like, how it operates, what it focuses on, and how it treats customers, employees, and shareholders. The four types of culture described in fig. 1 above demonstrates the means to realize the desired goals under each culture.

Under clan culture - Human Relations model. Cohesion and morals are the means to achieve Human Resource Development and empowerment. Adhocracy culture - Open System model:- flexibility and creativity leads to growth, resource and acquisition. Hierarchical culture - Information Management and communication is the means to stability and control. Market culture - Planning and goal setting leads to productivity and efficiency.

Organization culture must be adoptable to external environment for sustained competitive advantage. The Adhocracy culture and market culture have an external positioning thus have a great influence on organizational performance. However, the inward focus which includes control, order and stability must govern the innovative culture for effective results. Further the human resource development and empowerment must be a key basis since culture is about people's behaviors, beliefs. 
Culture types are modal or dominant ones rather than mutually exclusive ones and most firms can and do have elements of several types of cultures. Therefore it follows that identifying a typology of cultures also makes it possible to determine if organizations are dominated by one type or have attributes of several types and this has a relationship with their performance.

Adaptive cultures: i.e. cultures that are able to respond to changes in the environment are the key to good performance. The adhocracy and market cultures have these attributes making them more appropriate to drive organizational performance. However, for organizations that are relatively stable and fit with a relatively stable environment, and risk-taking and innovation are not necessarily successful. Too much change can lead to instability, low cost-efficiency, risky projects and a loss of sense of direction. Therefore it is advisable to have attributes of several types of cultures since all have impact to organizational performance.

For the performance of an organization to be influenced by culture values of the culture should be comprehensively shared.

Organizational culture has direct or indirect influence to performance which means a company should uphold the type of culture that will promote optimal performance.

\section{Recommendation}

Based on the findings of the study and the conclusion outlined above the following are the recommendations:

- Further study to be done to explore the factors that may reduce the gap between employees preferred organizational culture practices and their perception of the organization practices.

- A study to be done to determine any relationship between organizational culture and strategy implementation.

\section{References}

[1]. Daulatram B. Lund, (2003),"Organizational culture and job satisfaction", Journal of Business \& Industrial Marketing, Vol. 18 Iss: 3 pp. $219-236$

[2]. Denison, D. (1984). Bringing corporate culture to the bottom line. Organizational Dynamics, 13(2), 5-22.

[3]. Hofstede, G. (1980). Culture's Consequences. Sage, Beverly Hills, CA. Ismael, Yusof and Davoud (2010) “A Review Paper on Organizational Culture and Organizational Performance"

[4]. Jeniffer, David, Charles and Bernadette (2011) Organizational Culture And Performance In High-Technology Firms: The Effects Of Culture Content And Strength

[5]. Kotter, P. and Heskett, L. (1992). Corporate Culture and Performance, Macmillan, New York, NY.

[6]. Lim, B. (1995). Examining the organizational culture and organizational performance link. Leadership and Organizational Development Journal, 16(5), 16-21.

[7]. Marcoulides, G. and Heck, R. (1993). Organizational culture and performance: Proposing and testing a model. Organization Science, 4(2), 209-225.

[8]. Ogbonna, E and Harris, L. (2000). Leadership style, organizational culture and performance: Empirical evidence from UK companies. International Journal of Human Resources Management, 11(4), 766-788.

[9]. Ogbonna, E and Harris, L. (2002). Managing organizational culture: Insights from the hospitality industry. Human Resource Management Journal, 12(1), 22-53.

[10]. Rousseau, D. (1991). Quantitative assessment of organizational culture. Group and Organizations Studies, 15(4), 448-460.

[11]. Saffold, G.S. (1998). Culture Traits, Strength, and Organizational Performance: Moving beyond Strong Culture. The Academy of Management Review, Vol. 13, 546-558

[12]. Schein, E. H. (1990). Organizational culture. American Psychologist, 43 (2), 109-119.

[13]. Schein, E. H. (1995). Organizational culture. Campus Verlag, Frankfurt/New York

[14]. Sondergaard, M. (1994). Hofstede Consequences- A Study of Reviews, Citations and Replications, Special Issue on Cross-national Organization Culture. European Group for Organizational Studies, 15(3): 447-456.

[15]. Sackman, S. (1991). Uncovering culture in organizations. Journal of Applied Behavioral Science, 27(3), 295-317.

[16]. Scott, T., Mannion, R., Davis, H., and Marshall, M. (2003). The quantitative measurement of organizational culture in health care: A review of the available instruments. Health Services Research, 38(3), 923-945. 